\title{
Cardiovascular system and estrogen in menopause
}

\author{
Adriana Aparecida Ferraz Carbone/1 \\ (ii) Ricardo Santos Simões ${ }^{2}$ \\ Manoel João Batista Castello Girão \\ (iD) José Maria Soares Júnior² \\ (iD) Edmund Chada Baracat ${ }^{2}$
}

\begin{abstract}
1. Departamento de Morfologia e Genética, Escola Paulista de Medicina/Universidade Federal de São Paulo; São Paulo, Brasil. 2. Departamento de Ginecologia, Escola Paulista de Medicina/Universidade Federal de São Paulo; São Paulo, Brasil. 3. Departamento de Ginecologia e Obstetrícia, Hospital das Clínicas, Escola de Medicina da Universidade de São Paulo; São Paulo, Brasil.

Women are known to have a lower incidence of cardiovascular disease than men of the same age, but this benefit disappears after menopause. Thus the risk of cardiovascular disease (CVD) increases greatly after menopause when estrogen levels decrease. Women are typically about ten years older than men at the first presentation of atherosclerotic coronary heart disease, and this appears to be related to the decline in postmenopausal ovarian hormone concentrations.

Estrogen-mediated vascular actions are mainly attributed to estradiol and exerted by estrogen receptors (ER $\alpha, E R \beta$, and $G)$ through rapid and/or genomic mechanisms, but these effects depend on aging and vascular status. Thus estrogens can modulate vascular function by targeting estrogen receptors in endothelial and vascular smooth muscle cells. Estrogens induce the release of nitric oxide and prostacyclins, both vasodilators. They may also cause a reduction in endothelin and angiotensin II production, which are vasoconstrictors. In addition, estrogens also reduce inflammation and may reduce the secretion of pro-atherogenic cytokines such as tumor necrosis factor-alpha (TNF- $\alpha$ ) and may increase prostaglandin, which reduces oxidative stress and also platelet activation.

In experimental studies, $\mathrm{ER} \alpha$-acting estradiol promotes the release of vasoactive compounds such as nitric oxide (NO) and prostacyclin and shifts the angiotensin axis to angiotensin production ${ }^{1-7}$. The mechanisms underlying estradiol vascular function also include anti-inflammatory and epigenetic modifications. $17 \beta$-estradiol alters the transcriptomic profile of endothelial cells, and miRNA involvement in vascular function regulatory pathways reinforces assumptions about estrogen vascular actions.

There is currently evidence that women of any age with vasomotor symptoms have a worse cardiovascular risk profile (increased risk of CVD, coronary heart disease, or ischemic stroke) compared with women without vasomotor symptoms. Women with vasomotor symptoms have significantly higher systolic and diastolic blood pressure, higher circulating total cholesterol levels, and a higher body mass index than women without symptoms.

However, data from the Women's Health Initiative (WHI) study point to an association between menopausal hormone therapy (THM) and cardiovascular risk (CV). However, analyses of post hoc subgroups that stratified participants according to their age and time of menopause paved the way for a better understanding of the relationship between estrogen and cardiovascular risk.

Thus, reviews that evaluated CV risk or benefit after estrogen administration, considering various factors, such as time, dose, route of administration, and formulation of MHT. Thus, MHT onset time was a critical factor in CV risk assessment. Consistent with the "time hypothesis", healthy symptomatic women who started THM younger than 60 years or within ten years of the onset of menopause were shown to have reduced risk of coronary heart disease (CHD) and mortality from all causes. In particular, MHT therapy has been associated with improved subclinical signs of 
atherosclerosis. The risk of venous thromboembolism (VTE) was reduced when low doses of oral estrogen were used. In addition, transdermal hormone application significantly reduced CV risk compared with oral administration. The impact of MHT on the CV system was influenced by factors inherent to the specific regimen or individual patient. Therefore, the individualization of care is necessary ${ }^{8-13}$. Conclusion: Hormone therapy remains the most effective treatment for menopausal symptoms, but decisions are complex, requiring an assessment of benefits and risks and determining the best type, dose, and duration of treatment. Benefits outweigh risks for most women with bothersome symptoms of menopause or high risk of fracture if started when younger than 60 years or ten years after menopause onset. CV risk calculation should be considered by physicians to exclude patients with high CV risk, to whom MHT is contraindicated. Risk and benefit assessment in a patient-centered approach based on individual resources, health status, and personal preferences is important for safe and effective treatment.

\section{REFERENCES}

1. Biglia N, Cagnacci A, Gambacciani M, Lello S, Maffei S, Nappi RE. Vasomotor symptoms in menopause: a biomarker of cardiovascular disease risk and other chronic diseases? Climacteric. 2017;20(4):306-12.

2. Franco OH, Muka T, Colpani V, Kunutsor S, Chowdhury S, Chowdhury R. Vasomotor symptoms in women and cardiovascular risk markers: systematic review and meta-analysis. Maturitas. 2015;81(3):353-61.

3. Soares Júnior IM, Sorpreso IC, Baracat EC. Is hormone therapy during climacteric for all? Rev Assoc Med Bras. 2015;61(3):191-2.

4. Pereira Filho AS, Soares Júnior JM, Arkader J, Maciel GA, Baracat EC. Attitudes and practices about postmenopausal hormone therapy among female gynecologists in Brasil. Maturitas. 2005;51(2):146-53.

5. Cabanelas LA, Carbonel AA, Santos MA, Simões RS, Liberatori-Filho AW, Baracat EC, et al. Cardiomyocytes morphology and collagen quantification in the myocardium of female rats treated with isoflavones or estrogens. Rev Bras Ginecol Obstet. 2012;34(10):447-52.

6. Giordano MV, Galvão Ferreira PA, Giordano LA, Garcia de Almeida SM, Cestari do Amaral V, Simoncini T, et al. How long is the ovary relevant for synthesis of steroids after menopause? Gynecol Endocrinol. 2018;34(6):536-9.
7. Mahajan A, Patni R, Gupta V. Menopause and cardiovascular disease. J Midlife Health. 2019;10(2):55-6.

8. Mattioli AV, Sciomer S, Moscucci F, Maiello M, Cugusi L, Gallina S, et al. Cardiovascular prevention in women: a narrative review from the Italian Society of Cardiology working groups on 'Cardiovascular Prevention, Hypertension and peripheral circulation' and on 'Women Disease'. J Cardiovasc Med (Hagerstown). 2019;20(9):575-83.

9. Naftolin F, Friedenthal J, Nachtigall R, Nachtigall L. Cardiovascular health and the menopausal woman: the role of estrogen and when to begin and end hormone treatment. F1000Res. 2019;8. pii: F1000 Faculty Rev-1576.

10. Newson L. Menopause and cardiovascular disease. Post Reprod Health. 2018;24(1):44-9.

11. Novella S, Pérez-Cremades D, Mompeón A, Hermenegildo C. Mechanisms underlying the influence of oestrogen on cardiovascular physiology in women. | Physiol. 2019;597(19):4873-86.

12. Pinkerton JV, Conner EA, Kaunitz AM. Management of menopause and the role for hormone therapy. Clin Obstet Gynecol. 2019;62(4):677-86.

13. Villa P, Amar ID, Shachor M, Cipolla C, Ingravalle F, Scambia G. Cardiovascular risk/benefit profile of MHT. Medicina (Kaunas). 2019;55(9). pii: E571. 